\title{
EVOLUÇÃO DA LEGISLAÇÃO BRASILEIRA SOBRE RECURSOS HÍDRICOS
}

\author{
Flábio Gonçalves ${ }^{(a)}$, Ana Paula Vieira Marques ${ }^{(b)}$, Alessandra Batista ${ }^{(c)}$, João Donizete \\ Lima $^{(\mathrm{d})}$
}

\begin{abstract}
${ }^{(a)}$ Programa de Pós-Graduação em Geografia. Universidade Federal de Goiás - UFG. Regional Catalão. Contato: flabiogon@ yahoo.com.br. Mestrando do Programa de Pós-Graduação em Geografia.

${ }^{(b)}$ Programa de Pós-Graduação em Geografia. Universidade Federal de Goiás - UFG. Regional Catalão. Contato: anapavim@gmail.com. Mestranda do Programa de Pós-Graduação em Geografia.

(c) Programa de Pós-Graduação em Geografia. Universidade Federal de Goiás - UFG. Regional Catalão. Contato: alessandraatanasio@yahoo.com.br. Mestranda do Programa de Pós-Graduação em Geografia.

(d)Programa de Pós-Graduação em Geografia. Universidade Federal do Goiás - UFG. Regional Catalão. Contato: Donizeteufg@gmail.com. Professor Doutor do Programa de Pós-Graduação em Geografia.
\end{abstract}

\section{EIXO: BACIAS HIDROGRÁFICAS E RECURSOS HÍDRICOS: ANÁLISE, PLANEJAMENTO E GESTÃO}

\section{Resumo}

A água é vital à vida ao bem-estar social. A qualidade dos recursos hídricos necessita de políticas públicas à preservação das bacias, nascentes, pois somente a partir da educação ambiental será possível a manutenção desse recurso indispensável à vida. O objetivo dessa pesquisa é demonstrar como as leis podem subsidiar a Geografia na preservação das bacias. O desenvolvimento metodológico foi exploratório e forneceu informações sobre o objeto da pesquisa para apresentar hipóteses de possível solução do problema na tutela dos recursos hídricos. A base teórica foi a legislação e doutrinas. Os resultados alcançados demonstraram que as leis e a Geografia influenciam na preservação da água. Assim, foi possível verificar que não há necessidade de criação de novas leis e sim aplicar as já existentes. O resultado encontrado respondeu ao objetivo geral, porquanto, verificou-se que as políticas públicas são capazes de preservar os recursos hídricos.

Palavras-chaves: Políticas Públicas - Recursos Hídricos - Geografia.

\section{Introdução}

Segundo Tundisi (2014), existe no Brasil cerca de 12\% das águas doces disponíveis em todo o planeta Terra. Tais recursos, estão distribuídos de forma irregular no território brasileiro, que vai de $5^{\circ} \mathrm{N}$ a $34^{\circ} \mathrm{S}$ de latitude, e estes estão sob a influência de uma ampla variedade de processos climatológicos que regulam a distribuição e a disponibilidade da água, sendo a precipitação anual média, segundo dados históricos 1962-2007 (ANA 2011), de 1.765 mm, que varia de região para região, no nordeste é de $500 \mathrm{~mm} / \mathrm{ano}$ e chegando a $3.000 \mathrm{~mm} / \mathrm{ano}$ na região Amazônica.

Atualmente, a questão relativa a água não se resume a discussão dos problemas atinentes a quantidade de água disponível e adequada para o consumo humano de animais e plantas. O problema é bem mais sério e amplo que isto. Como por exemplo, a distribuição no mundo das reservas de água potável, será suficiente até quando para abastecer a população com qualidade? O descaso histórico dos governantes 
em relação ao aquecimento global, a desertificação, a situação de vários povos que já não têm acesso à água limpa e potável, a poluição das águas com resíduos químicos e industriais, a morte de rios nas grandes cidades, enfim, são tantas as questões que envolvem o uso da água.

A água e todos os demais bens naturais são patrimônio da humanidade, de toda a sociedade. Qual é o papel do cidadão nesta tarefa de preservação do meio ambiente para as presentes e futuras gerações? Quais os meios postos à disposição do cidadão para alcançar efetividade na preservação ambiental?

O trecho abaixo traz reflexão sobre o tema:

A vida como momento de alta complexidade e auto-organização da matéria é um capítulo da história do universo. E a vida humana, um subcapítulo da história da vida. Todos somos interdependentes. Assim nos encaixamos no conjunto de todos os seres. Por isso, a rigor, não existe um meio ambiente puro. [...] $\mathrm{O}$ ser humano, porém, possui uma singularidade: ele intervém nos processos da natureza, dialoga com ela e molda-a conforme um determinado projeto. (SILVA, 2003, p.9-10)

O cidadão, a sociedade civil organizada em associações de defesa do meio ambiente, as organizações não governamentais imbuídas desta nova visão do homem e do meio ambiente devem fiscalizar, agir, protestar, usar de todos os recursos legais para intervir no sistema político, administrativo, legislativo e judiciário. Esta intervenção tem por fim buscar a efetiva existência do meio ambiente: saudável, seu uso sustentável, qualidade de vida e bem-estar para todos, em especial, para as gerações futuras.

Com o exposto acima, neste trabalho buscou-se analisar a legislação pátria acerca do uso dos recursos hídricos, para com isto, verificar se esta é suficiente para garantir o uso sustentável da água, visto que este é o desejo da Geografia, a qual estuda a preservação dos recursos hídricos à luz da Constituição Federal de 1988, sendo que, o conhecimento da legislação é primordial para que os recursos sejam preservados a contento para a Geografia.

Além desta análise, estudar-se-à os princípios constitucionais que fazem a conformação de todo o ordenamento jurídico. Eles são dirigentes da interpretação e aplicação das leis, auxiliam ao legislador e demais aplicadores do direito a buscarem o justo emprego das normas, sobretudo daquelas relativas ao meio ambiente, e à água, fundamental para a manutenção da vida no planeta.

\section{Legislação sobre água no Brasil}

A água, um recurso natural e essencial à vida é também indispensável ao desenvolvimento econômico e ao bem-estar social, todavia, o seu consumo descontrolado, o aumento das populações, as irrigações, o lançamento de efluentes domésticos e industriais, a sua utilização para gerar energia e para o lazer, entre outros vêm degradando esse bem comum (BERNARDES, 2007). 
No início do século XX, o mundo passou por uma crise econômica de grande proporção, vários países tiveram suas economias afetadas, principalmente Estados Unidos da América (EUA), que era grande consumidor de produtos agrícolas do Brasil, em especial o café. Neste contexto, os Estados Unidos deixaram de comprar o café brasileiro, o que obrigou o Brasil a tomar medidas radicais, conforme foi a queima de toneladas de café devido a crise de 1929.

O uso de recursos naturais, como a água, era cada vez mais acentuado, visto que toda indústria precisa de energia elétrica para movimentar seus equipamentos, clarear o ambiente, etc. Além de consumir a água para suprir outras necessidades. Assim, se tornou imprescindível a elaboração de leis e regras para disciplinar o uso dos recursos hídricos, tornando este uma faceta do nosso ordenamento jurídico.

A primeira lei a tratar do uso da água foi o Decreto n. 24.643, de 10 de julho de 1934, em que se buscou dar uma legislação mais adequada às necessidades que se apresentavam à época do decreto, como o aumento da demanda por energia elétrica e da água potável para consumo da população que migrou para as cidades para trabalhar nas indústrias.

O Decreto n. 24.643/34, Código das Águas, tratou do uso da água, de sua propriedade, quais águas seriam públicas, comuns ou particulares. O legislador se preocupou em editar uma norma que permitisse ao Estado controlar e incentivar o aproveitamento industrial das águas. Esse decreto revela a especial atenção dada na época à necessidade de se privilegiar o desenvolvimento industrial, mas procurando garantir a racionalidade do aproveitamento da água. $\mathrm{O}$ decreto definiu as competências em relação águas públicas de uso comum, dividindo-as entre União, Estados e Municípios, a fim de facilitar a fiscalização e controle da sua utilização, bem como impor limites garantindo a autonomia de cada ente da federação dando, por exemplo, aos estados a competência para autorizar ou conceder o aproveitamento industrial das quedas d'água e outras fontes de energia hidráulica.

É pertinente destacar que o artigo 36, §2, permitiu a retribuição financeira pelo uso de águas públicas, por parte de usuários. Este é um dado importante, pois à época não se tinha plena noção de que os recursos hídricos não eram renováveis, as pessoas ainda imaginavam que água era infinita e seu uso livre e despreocupado. O decreto em seus artigos. 98, 109, 110 e 111, tratam efetivamente de medidas de proteção aos recursos hídricos, trazendo uma série de proibições e limitações, tais como proibição de construir, se esta construção fosse potencialmente poluidora da água, proibiu de sujar ou contaminar água que não usa em prejuízo de terceiro. Ainda, impunha aos infratores responsabilidade criminal, civil de reparação dos danos, quando houvessem, e administrativas como multas.

$\mathrm{O}$ artigo 111, do decreto, determina a necessidade de se fazer o tratamento das águas utilizadas nas indústrias e na agricultura, antes de serem devolvidas aos rios, havendo necessidade de expressa autorização para seu uso. Contudo, esta autorização da poluição de águas a bem da agricultura e 
indústria, transferindo ao setor privado a responsabilidade de minimizar o impacto ambiental, não estabeleceu linhas ou indicações básicas para esta minimização.

O código das águas de 1934 foi um marco histórico na proteção dos recursos hídricos, deixando a base para as futuras leis sobre o tema e alguns importantes conceitos que foram sedimentos ao longo do tempo em outras normas de proteção ao meio ambiente.

\section{Lei da Política Nacional de Meio Ambiente}

A Lei n. 6.938 de 1981 é importante no sentido de estruturar a política de meio ambiente por meio da criação de sistemas e entidades para articular e dar suporte institucional e técnico para a gestão ambiental no país, tornando mais efetiva a atuação do Estado.

Com o intuito de atender a vários princípios relacionados à questão ambiental, em especial a racionalização do uso dos recursos naturais, tais como solo, subsolo, água e ar, foi criado o Sistema Nacional do Meio Ambiente (SISNAMA), pela Lei n. 6.938 de 31 de agosto de 1981 que dispõe ser o SISNAMA um conjunto articulado de órgãos, entidades, regras e práticas responsáveis pela proteção e pela melhoria da qualidade ambiental.

A Resolução n. 20/86 do Conselho Nacional do Meio Ambiente (CONAMA) trouxe a classificação das águas em doce, salobra e salina. Com a finalidade de privilegiar a utilização responsável dos diversos tipos de água, constituindo parâmetros técnicos que assegurassem esse uso correto, de maneira a reduzir os custos de controle da poluição e tornando adequado o uso de corpos d'água ou seus trechos de acordo com suas finalidades preponderantes.

A Resolução ainda propõe que o enquadramento dos corpos d'água deve estar baseado não necessariamente no seu estado atual, mas nos níveis de qualidade que deveriam possuir para atender às necessidades da comunidade. O maior interesse desta classificação é proteger não só a saúde e o bemestar humano, mas também, o equilíbrio ecológico aquático que são afetados em consequência da perda da qualidade das águas.

Com a necessidade das comunidades utilizarem cada vez mais os recursos hídricos, trouxe consigo a obrigação de se pensar em leis mais eficazes, além de meios de prevenção à poluição e conscientização das pessoas, por meio de fiscalização e educação ambiental. O surgimento de diferentes e significativas atividades econômicas resultaram no estabelecimento de critérios de repartição de competências, como o criado na lei que instituiu a política Nacional de Meio Ambiente e mais tarde a própria Constituição Federal, que sedimentou a importância e necessidade de proteção ambiental. 
[...] A cada ano, a quantidade de água doce vem sendo reduzida devido ao aumento da temperatura, que causa o degelo daquelas áreas e aumenta em milímetros por ano o volume das águas salgadas dos oceanos. A previsão é de que haja aceleração desse processo. Em reservatórios subterrâneos profundos estão $29,9 \%$ da água doce, e apenas $1,2 \%$ está nos rios, lagos e demais reservatórios, com volume aproximado de 136.800 $\mathrm{km}^{3}$. (SENRA, 2001, p. 133).

\section{Constituição Federal de 1988 e os comandos gerais normativos aos Recursos Hídricos}

A promulgação da Constituição Federal de 1988, trouxe um novo parâmetro relativo às questões ambientais, em especial os recursos hídricos, fundamentais à sadia qualidade de vida e tão importante para a atual geração e as futuras. A água por ser um dos elementos essenciais à manutenção da vida, está amparada pelo artigo 225 da Constituição Federal de 1988.

A Constituição estendeu este direito a todos, não delimitando os destinatários, ao contrário, deu um sentido universalista a expressão "todos". E segundo Fiorillo (2008, p. 10-12) a concepção de todos traz a característica de bem difuso, consoante o que estabelece o artigo $5^{\circ}$ da Constituição Federal.

A Carta traz os princípios fundamentais que deverão guiar o uso dos recursos naturais, bem como sua proteção. No caput, já fica estabelecido que ao poder público seja imposta a responsabilidade e o dever de preservação e defesa do meio ambiente. Neste ponto a Constituição recepcionou importantes diplomas legais que tratam de questões ambientais, dentre eles a Lei n. 6.938/81, e mais ainda, o legislador cria a competência legislativa concorrente, permitindo que não só a União, como também, os Estados e Municípios legislem sobre matéria ambiental, buscando ampliar a efetividade da proteção, sobretudo apurar as responsabilidades por danos ambientais e punir os infratores.

Uma das consequências desta mudança de paradigma são os dispositivos que dão o domínio de rios e lagos internacionais ou que banhem mais de um Estado a União e aos Estados o domínio de águas superficiais ou subterrâneas, fluentes, emergentes ou em depósito, exceto as pertencentes ou decorrentes de obras da União. Assim, nova classificação dos recursos hídricos se impôs, extinguindo as águas em regime privado e o domínio dos municípios.

Os princípios dão um norte ao poder público, pois indicam o que deve ser feito e como deve ser o tratamento dado as questões relativas ao meio ambiente. São alguns dos princípios ambientais na Constituição: o desenvolvimento sustentável, do poluidor-pagador, da prevenção e da participação. Estes princípios aliados a outros direitos fundamentais, tais como o direito à informação, que é um dever do poder público para com o cidadão, são instrumentos indispensáveis à participação da sociedade e formação de uma consciência ambiental. 


\section{Leis, Órgãos e o Gerenciamento dos Recursos Hídricos no Brasil}

A Lei n. 9.433/97 institui a Política Nacional de Recursos Hídricos, regulamentou o inciso XIX do artigo 21 da Constituição Federal. A tem como fundamentos: a água como um bem de domínio público, um recurso natural limitado e dotado de valor econômico, estabeleceu uso prioritário, em situações de escassez, para consumo humano e animal, a gestão dos recursos hídricos de forma a propiciar o uso adequado das águas, a delimitação da bacia hidrográfica como unidade territorial a fim de implementar a Política Nacional de Recursos Hídricos, a descentralização da gestão desses recursos, a participação do Poder Público, dos usuários e das comunidades na gestão.

O gerenciamento dos recursos hídricos tem uma longa história. A barragem mais antiga conhecida no mundo foi construída no Egito cerca de 5 mil anos atrás, tendo sido usada para armazenar água para beber e para a irrigação. Nessa mesma época, na Arábia, agricultores usavam as crateras de vulcões extintos como tanques de armazenagem e cavavam poços profundos para buscar água potável. Escavações em ruínas na Índia, da mesma idade, revelaram os restos de sistemas de drenagem e suprimento de água, osquais incluíam banheiras e piscinas. Os antigos gregos estavam conscientes da importância da qualidade da água, e Hipócrates alertava sobre a necessidade de filtrar e ferver a água de beber. (BROWN, 2000, p.10).

Consoante aos princípios constitucionais e da Conferência Rio/92, esta lei se caracteriza por reconhecer que os recursos hídricos não são infinitos, ao contrário, são vulneráveis ao uso incorreto e indiscriminado pelo homem, que não se preocupou por séculos com a poluição e escassez de água, crendo ser ela um recurso inacabável. Mas, também, a lei em seu regramento, dotou os órgãos públicos responsáveis pela gestão ambiental de instrumentos e medidas que possibilitam um controle e fiscalização do uso da água buscando aliar o desenvolvimento econômico à sustentabilidade e apropriado ao manejo da mesma, pois definiu os instrumentos mínimos para a gestão dos recursos hídricos enumerando-os no artigo $5^{\circ}$.

A Lei n. 9.433/97 também criou o Sistema Nacional de Gerenciamento de Recursos Hídricos e estabelece uma nova política fazendo com que a administração, fiscalização e uso das águas sejam de forma compartilhada e democrática entre os entes federados. Assim, foram criados órgãos, conselhos e comitês para desenvolverem e gerenciarem aos recursos hídricos com a maior amplitude e eficácia possível, o que a lei previu em seu artigo 33.

O Conselho Nacional de Recursos Hídricos (CNRH), e o Sistema Nacional de Gerenciamento de Recursos Hídricos (SINGREH) têm caráter normativo e deliberativo, de acordo com a Lei tem atribuições de promover a articulação do planejamento de recursos hídricos em âmbito nacional com os planejamentos regionais, estaduais e dos setores usuários, além de analisar propostas de alteração da legislação pertinente a recursos hídricos e à Política Nacional de Recursos Hídricos estabelecendo 
diretrizes complementares para a implementação da Política Nacional de Recursos Hídricos e para a aplicação dos instrumentos de atuação do Sistema Nacional de Gerenciamento de Recursos Hídricos.

É tarefa do Conselho Nacional, acompanhar a execução e aprovar o Plano Nacional de Recursos Hídricos e determinando as providências necessárias para o cumprimento das suas metas, estabelecendo os critérios gerais para a outorga e cobrança de direitos de uso de recursos hídricos.

O CNRH como órgão máximo da gestão dos recursos hídricos no Brasil tem como um dos seus objetivos exercer a função de integrar e articular as políticas públicas, buscando especialmente a harmonização do gerenciamento de águas de diferentes domínios.

Além do órgão federal existem os Conselhos Estaduais de Recursos Hídricos que definem os fundamentos e diretrizes da Política de Recursos hídricos de cada estado, que deverá respeitar e acompanhar as deliberações da Política Nacional, definidas pelo Conselho Nacional (CN) e pela Agência Nacional de Águas (ANA).

As diretrizes dos conselhos estaduais são dadas pelo CNRH e pela ANA, são órgãos colegiados, integrante do SINGREH de cada estado, com atribuições normativas, consultivas e deliberativas. A principal finalidade e objetivo dos conselhos é a valorização dos corpos d'água de domínio estadual, bem como estabelecer os parâmetros para a outorga e cobrança do direito de uso da água, além de promover a articulação, integração e coordenação da atividade estadual em relação aos recursos hídricos, a fim de viabilizar o seu uso sustentável e a participação dos usuários nas decisões e projetos estaduais e particulares relacionados ao uso da água.

A análise da proposta de criação dos comitês de Bacia Hidrográfica no Estado, a orientação da implantação da Política Estadual de Recursos Hídricos, a aplicação de seus instrumentos e a atuação do Sistema Estadual de Gerenciamento de Recursos Hídricos são de responsabilidade dos conselhos estaduais, bem como outras atividades inerentes às particularidades de cada estado da federação. Entre os gestores dos recursos hídricos existem os Comitês de Bacia Hidrográfica que desempenham importante papel na efetivação da política de gerenciamento dos recursos hídricos, visto que descentraliza a gestão das águas e facilita a participação da sociedade nesta gestão.

Os Comitês são destinados a atuar como "parlamento regional das águas", visto que se caracteriza como um fórum de discussão e decisão no âmbito de cada bacia hidrográfica e tem como atribuição legal administrar os recursos hídricos da região na qual atua. Além de promover o debate das questões relacionadas aos recursos hídricos da bacia; deve articular a atuação das entidades que atuam nas questões relativas à água na busca da união dos interessados em favor de intervenções práticas com intuito de solucionar os problemas e viabilizar melhores condições ambientais na bacia hidrográfica. 
A Agencia Nacional das Águas (ANA) foi criada pela Lei n. 9.984/00 e foi definida como entidade federal responsável pela implementação da Política Nacional de Recursos Hídricos e pela coordenação do Sistema Nacional de Gerenciamento de Recursos Hídricos, foi um dos marcos, quanto à proteção dos recursos hídricos. Esta lei estabeleceu regras para a atuação da agência de águas bem como criou sua estrutura administrativa e instituiu suas fontes de recursos.

De acordo com Freitas (2002), a ANA além de classificar as águas dos rios e das represas e definir o que deve ser destinado ao consumo, entre outras competências, tem também a missão de executar e coordenar a gestão compartilhada e integrada dos recursos hídricos e regular o acesso a água, promovendo o seu uso sustentável em benefício da atual e das futuras gerações.

A partir da ANA sedimentou-se em um sistema de gestão de recursos hídricos, que se divide em três grandes núcleos: políticas públicas voltadas para a proteção e uso racional da água, o planejamento de ações e a gerenciamento do sistema como um todo.

Tem-se ainda como atribuição da ANA, estimular e apoiar as iniciativas voltadas para a criação de Comitês de Bacia Hidrográfica, bem como o planejamento e a promoção de ações destinadas a prevenir ou minimizar os efeitos de secas e inundações, no âmbito do Sistema Nacional de Gerenciamento de Recursos Hídricos, em articulação com o órgão central do Sistema Nacional de Defesa Civil, em apoio aos Estados e Municípios. A organização e implantação e gerenciamento do Sistema Nacional de Informação sobre Recursos Hídricos, garantem o acesso da coletividade aos temas relativos ao uso da água.

As Agências de Águas que são entes dotados de personalidade jurídica, sem fins lucrativos têm por finalidade exercer a função de secretaria executiva do respectivo comitê ou respectivos comitês, o qual ou quais fizeram sua solicitação, consoante o que dispõe o art. 43 da Lei n. 9.433/97, de bacia hidrográfica ao qual é vinculada, de maneira que preste a ele o suporte técnico necessário.

Compete às Agências de Água de acordo com seu âmbito de atuação manter balanço atualizado da disponibilidade de recursos hídricos realizando cadastro de usuários, cobrando pelo seu uso, podendo fazê-lo por meio de delegação. Cabe ainda analisar e emitir pareceres sobre projetos e obras que envolvam uso da água, fazer o acompanhamento da utilização e administração dos recursos financeiros inclusive elaborando proposta orçamentária e o Plano de Recursos Hídricos que serão submetidos aos respectivos comitês de bacias. É papel das agências celebrarem convênios e gerir o Sistema de Informações sobre Recursos hídricos dentre outras competências. De todo o aparelhamento que o estado proporciona não há como conseguir preservar os recursos hídricos sem a presença do cidadão na vanguarda de toda a legislação, e nesse sentido a Constituição Federal de 1988 atribuiu a participação da sociedade na proteção dos recursos naturais. 
Diante disto pode-se afirmar que avanços ocorreram na gestão hídrica brasileira, contudo, ainda é fundamental salientar que a matriz industrial brasileira apóia-se no uso intensivo dos recursos hídricos e, esta condição está na base do nosso método de desenvolvimento, tornando-se indispensável que a gestão integrada desses recursos esteja inserida entre as prioridades nacionais.

\begin{abstract}
Nessa perspectiva panorâmica e considerando a juventude da nossa legislação de águas, o déficit de gestão pré-existente a ela, o passivo ambiental herdado das gerações passadas e a complexa engenharia política necessária para a construção de um Sistema Nacional de Gerenciamento de Recursos Hídricos, num país federativo e de dimensões continentais, é lícito, sim, comemorar, como sugere Machado (2008), os avanços alcançados até este momento na PNRH (SILVA JUNIOR, 2009, p. 58/59)
\end{abstract}

\title{
6. O cidadão e a preservação dos recursos hídricos
}

A Constituição de 1988 determina que na defesa do meio ambiente devem atuar o Estado e também a sociedade, à coletividade é imposto o dever de proteger e preservar os recursos naturais. Neste sentido, Carta Magda apresenta ao cidadão instrumentos, mecanismos para efetivar sua participação. A sociedade pode se organizar por meio de associações, Organizações Não Governamentais, sindicatos, até mesmo de forma individual.

O meio ambiente saudável é um direito fundamental ao ser humano, consoante Silva (2002, p. 821) "as normas constitucionais assumiram a consciência de que o direito à vida, como matriz de todos os demais direitos fundamentais do homem, é que há de orientar todas as formas de atuação no campo da tutela do meio ambiente".

Dentre os meios de participação do cidadão, nas questões relativas a meio ambiente por meio do poder judiciário, previstos na Constituição, está a ação popular (art. 5º, LXXIII), o mandado de segurança coletivo (art.5 $5^{\circ}$ LXX, b), o mandado de injunção (art. $5^{\circ}$, LXXI), etc. O próprio conceito de cidadania tem se ampliado, para incluir não só o eleitor, mas a todos que podem se valer de instrumentos jurídicos ou políticos para viabilizar os direitos e garantias fundamentais individuais e sociais. Milaré (2007), ressalta que o envolvimento cada vez maior da comunidade é fruto "da tomada de consciência da situação, do amadurecimento político das instituições e das pessoas, assim como da estimulante solidariedade com a Terra".

Contudo, este não é o único modo da sociedade participar, antes mesmo das questões ambientais chegarem ao judiciário a comunidade pode participar como acontece na iniciativa popular de projeto de lei, ou seja, participa na formação das leis, interfere na vontade do legislador. Por intermédio das associações civis e de defesa do meio ambiente, também pode colaborar na formação do próprio direito ambiental. 
A cidadania, atualmente, traduz-se na participação da sociedade no Estado, buscando efetivar a verdadeira Democracia. A democracia participativa para Carvalho (2008, p. 653) "deve ser valorizada não como substitutiva da democracia indireta ou representativa, mas como técnica capaz de corrigir os excessos e as insuficiências da representação política".

O Brasil, para preservar os corpos hídricos e garantir o acesso a eles, deverá promover uma gestão eficiente, que procure a homogeneização inter-regional e intertemporal da água. É fundamental o conhecimento das necessidades dos diversos usuários e da capacidade de oferta e de renovação das fontes naturais, para que haja uma definição dos marcos regulatórios principais e da capacidade de suporte de cada bacia (FREITAS e SANTOS, 1999).

\section{Conclusão}

A utilização sustentável da água, sua preservação de maneira que seja racional o seu uso, demanda uma gestão séria e comprometida com o futuro da existência deste recurso. Desta forma o sistema de gerenciamento de recursos hídricos, as leis e os órgãos governamentais precisam permitir aos cidadãos papel ativo nesta tarefa. E garantir que a população atual tenha acesso a água potável, própria para o consumo, mas que as futuras gerações também o tenham.

Planejamento do uso, controle e proteção dos recursos hídricos são fundamentais para o sucesso da Política Nacional de Recursos Hídricos. A efetivação deste controle se dá por meio da formação das bacias hidrográficas. A criação da ANA promoveu um grande avanço quanto à proteção dos recursos hídricos. Entretanto, somente esforços governamentais distanciados da participação popular não são suficientes. O cidadão tem que participar efetivamente.

A participação da sociedade deve ser estimulada e facilitada, todos devem ter acesso a informação, aos estudos sobre sustentabilidade do uso dos recursos naturais, aos projetos relacionados ao seu uso. A educação ambiental deve estar presente desde a mais tenra idade, a fim de formar cidadãos conscientes e capazes de participar e é esse um dos principais papeis da Geografia, que além de ensinar o ser humano o que é espaço, sociedade, deve também nas disciplinas primárias conscientizar a criança o que são recursos hídricos, o que é sustentabilidade e principalmente consolidar os conceitos de meio ambiente.

A evolução da proteção ambiental pressupôs a mudança de vários paradigmas até então sedimentados, como a ideia de que os recursos naturais são infinitos. Estas mudanças demandaram tempo, a evolução foi lenta e ainda há que se lutar contra pensamentos equivocados que estão arraigados na sociedade. É preciso investimento em educação e medidas de proteção ambiental efetivas, é necessário que os custos do uso dos recursos ambientais sejam efetivamente cobrados daqueles que fazem uso 
irresponsável da água. Daí a necessidade do princípio do poluidor-pagador garantindo que as atividades produtivas e potencialmente degradantes do meio ambiente sejam compatíveis com a proteção ambiental, porquanto, a água é um bem, dotado de valor econômico, social e político.

O direito de acesso aos recursos hídricos, com o estabelecimento de algumas prioridades, é imprescindível para a manutenção da viabilidade de utilização destes recursos. O interesse coletivo deve se sobrepor ao interesse privado ou econômico, visto que a água como fonte essencial à vida e ao meio ambiente é um bem de uso comum do povo, podendo ser desfrutada desde que respeite os limites constitucionais e legais.

Ademais, o uso dos recursos naturais deve privilegiar sempre a preservação ambiental, sob pena de comprometer o futuro das águas. A utilização da gestão descentralizada é fundamental, pois pressupõe que todos os interessados tenham a possibilidade de conhecer e opinar em relação ao uso da água, seja em âmbito regional, local ou nacional, na medida em deve-se favorecer a discussão em todos os segmentos da sociedade.

Cabe ressaltar que a legislação acerca da proteção aos recursos ambientais está cada vez mais moderna e condizente com a necessidade atual de prevenção dos danos ambientais e preservação destes recursos para as gerações futuras, contudo, ainda são necessários mais investimentos governamentais no sentido de efetuar políticas públicas mais eficazes de proteção ambiental, bem como favorecer a participação popular consciente. Esta participação somente se tornará mais efetiva se houver a preparação do cidadão por meio de programas de educação e conscientização ambiental.

\section{Bibliografia}

BERNARDES, M. B. J. Bacia hidrográfica do rio uberabinha: a disponibilidade de água e uso do solo sob a perspectiva da educação ambiental. 2007, 221 f. Tese (doutorado) - Universidade Federal de Uberlândia,

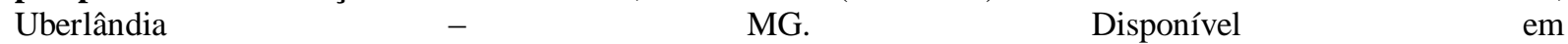
<http://www.ppgeo.ig.ufu.br/sites/ppgeo.ig.ufu.br/files/Anexos/Bookpage/Anexos_MariaBeatrizJunqueiraBerna rdes.pdf>. Acesso em 16/02/2017.

BRASIL. Decreto n. 24.643, de 10 de julho de 1934, decreta o Código de Águas. Diário Oficial da República Federativa do Brasil, Brasília (DF), 10 de jul. 1934.

. Lei n. 6.938, de 31 de agosto de 1981, Dispõe sobre a Política Nacional do Meio Ambiente, seus fins e mecanismos de formulação e aplicação, e dá outras providências. Diário Oficial da República Federativa do Brasil. Brasília, DF, 10 ago. 1934. Disponível em: http://www.in.gov.br. Acesso em: 26 fev. 2017.

Edipro, 2016.

Constituição (1988). Constituição da República Federativa do Brasil. 25. ed. Rio de Janeiro:

Lei 9.433, de 08 de janeiro de 1997, Institui a Política Nacional de Recursos Hídricos, cria o Sistema Nacional de Gerenciamento de Recursos Hídricos, regulamenta o inciso XIX do art. 21 da Constituição Federal, e altera o art. $1^{\circ}$ da Lei $n^{\circ} 8.001$, de 13 de março de 1990, que modificou a Lei $n^{\circ} 7.990$, de 28 de dezembro de 1989. Diário Oficial da República Federativa do Brasil. Brasília, DF, 08 jan. 1997. Disponível em: http://www.in.gov.br. Acesso em: 26 fev. 2017. 
Lei n. 9.984 de 17 de julho de 2000, Dispõe sobre a criação da Agência Nacional de Águas - ANA, entidade federal de implementação da Política Nacional de Recursos Hídricos e de coordenação do Sistema Nacional de Gerenciamento de Recursos Hídricos, e dá outras providências. Diário Oficial da República Federativa do Brasil. Brasília, DF, 17 jul. 2000. Disponível em: http://www.in.gov.br. Acesso em: 26 fev. 2017.

. Resolução Conama n. 20 de 18 de junho de 1986 que dispõe: O CONSELHO NACIONAL DO MEIO AMBIENTE - CONAMA, no uso das atribuições que lhe confere o art. $7^{\circ}$, inciso $1 X$, do Decreto 88.351 , de $1^{\circ}$ de junho de 1983, e o que estabelece a RESOLUÇÃO CONAMA No 003, de 5 de junho de 1984. Diário Oficial da República Federativa do Brasil. Brasília, DF, 30 jul. 1986. Disponível em: http://www.in.gov.br. Acesso em: 26 fev. 2017.

BROWN, G. et al. Os recursos físicos da Terra. Bloco 4 Recursos hídricos. Tradução e adaptação: Álvaro P. Crosta. Campinas: Editora da Unicamp, 2000.

CARVALHO, K. G. Direito constitucional.14. ed. Belo Horizonte: Del Rey, 2008. p. 653.

FIORILlO, C. A. P. Curso de direito ambiental brasileiro. 9. ed. São Paulo: Saraiva, 2008. p. 10-12.

FREITAS, M. A. V. Introdução ao gerenciamento dos recursos hídricos.3. ed. Brasília: Agência Nacional de Energia Elétrica \& Agência Nacional de Águas, 2002. 328p.

M. A. V.; SANTOS, A. H. M.. Importância da Água e da Informação Hidrológica. In: O Estado das Águas no Brasil. Brasília: ANEEL e ANA, 1999.

MILARÉ, E. Direito do ambiente: doutrina, jurisprudência, glossário. 5. ed. São Paulo: Revista dos Tribunais, 2007. p. 184.

SENRA, J. B. Água o desafio do terceiro milênio. In: VIANA, G.; SILVA, M.; DINIZ, N. O desafio da sustentabilidade: um debate socioambiental no Brasil. São Paulo: Fundação Perseu Abramo, 2001. p. 133 155.

SILVA, J. A. da. Curso de direito constitucional positivo. 21. ed. São Paulo: Malheiros, 2002. p. 821.

SILVA, O. F.da. Direito ambiental e ecologia: aspectos filosóficos contemporâneos. Barueri-SP: Manole, 2003. p. 9-10.

SILVA J. C. C. Análise da situação da gestão de recursos hídricos no distrito industrial de Uberlândia - MG: o modelo da Souza cruz s/a. 2009, 202 f. Dissertação (mestrado). Universidade Federal de Uberlândia, Uberlândia. Disponível em $<$ http://www.ppgeo.ig.ufu.br/sites/ppgeo.ig.ufu.br/files/Anexos/Bookpage/Anexos_ClovisCruvineldaSilvaJunior. pdf> Acesso em 14/03/2017.

TUNDISI, J. G. (coordenador). Recursos hídricos no Brasil: problemas, desafios e estratégias para o futuro. Rio de Janeiro: Academia Brasileira de Ciências, 2014. 76 p. Disponível em <http://www.abc.org.br/IMG/pdf/doc-5923.pdf> acesso em 16/02/2017. 